\title{
Association Between Psychiatric Comorbidities and Mortality in Epilepsy
}

Gerard Tao, MD*, Clarissa Auvrez, MD*, Russell Nightscales, BSc(Hons), Sarah Barnard, MIPH, Lara McCartney, MBBS, Charles B. Malpas, PhD, Piero Perucca, MD, Zhibin Chen, MBiostat, PhD, Sophia Adams, MBBS, Anne McIntosh, PhD, Sophia Ignatiadis, MSc, Patrick O'Brien, MBBS, Mark J. Cook, MD, Patrick Kwan, MD, Samuel F. Berkovic, MD, Wendyl D'Souza, MBChB, PhD, Dennis Velakoulis, MBBS, and Terence J. O'Brien, MD

Neurology: Clinical Practice October 2021 vol. 11 no. 5 429-437 doi:10.1212/CPJ.0000000000001114

\section{Correspondence}

Dr. O'Brien

te.obrien@alfred.org.au

\section{Abstract}

\section{Objective}

To explore the impact of psychiatric comorbidities on all-cause mortality in adults with epilepsy from a cohort of patients admitted for video-EEG monitoring (VEM) over 2 decades.

\section{Methods}

A retrospective medical record audit was conducted on 2,709 adults admitted for VEM and diagnosed with epilepsy at 3 Victorian comprehensive epilepsy programs from 1995 to 2015. A total of 1,805 patients were identified in whom the record of a clinical evaluation by a neuropsychiatrist was available, excluding 27 patients who died of a malignant brain tumor known at the time of VEM admission. Epilepsy and lifetime psychiatric diagnoses were determined from consensus opinion of epileptologists and neuropsychiatrists involved in the care of each patient. Mortality and cause of death were determined by linkage to the Australian $\mathrm{Na}$ tional Death Index and National Coronial Information System.

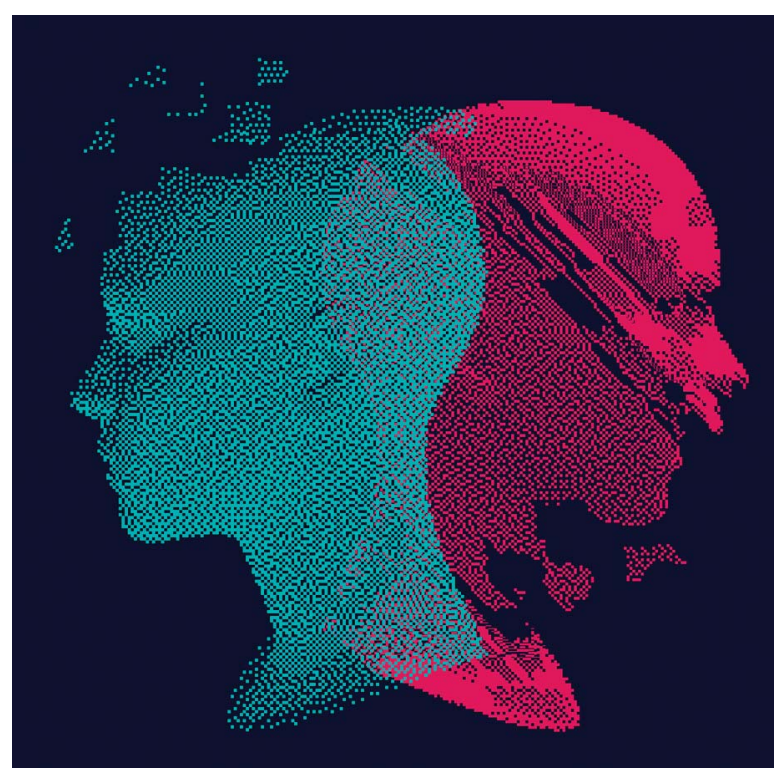

\section{Results}

Compared with the general population, mortality was higher in people with epilepsy (PWE) with a psychiatric illness (standardized mortality ratio [SMR] 3.6) and without a psychiatric illness (SMR 2.5). PWE with a psychiatric illness had greater mortality compared with PWE without (hazard ratio 1.41, 95\% confidence interval 1.02-1.97) after adjusting for age and sex. No single psychiatric disorder by itself conferred increased mortality in PWE. The distribution of causes of death remained similar between PWE with psychiatric comorbidities and those without.

\section{Conclusion}

The presence of comorbid psychiatric disorders in adults with epilepsy is associated with increased mortality, highlighting the importance of identifying and treating psychiatric comorbidities in these patients.

*These authors contributed equally to this work as co-first authors.

Departments of Medicine and Neurology (GT, CA, RN, CBM, PP, ZC, AM, PK, TJO), The Royal Melbourne Hospital, The University of Melbourne; Department of Neuroscience (RN, SB, CBM, PP, ZC, AM, PK, TJO), The Alfred Hospital, Monash University Central Clinical School, Melbourne; Melbourne Neuropsychiatry Centre (LM, SA, DV), Department of Psychiatry, The Royal Melbourne Hospital, The University of Melbourne; Departments of Medicine and Neurology (SI, POB, MJC, WDS), St. Vincent's Hospital Melbourne, The University of Melbourne; and Department of Medicine (Neurology) (SFB), The University of Melbourne (Austin Health), Victoria, Australia.

Funding information and disclosures are provided th the end of the article. Full disclosure form information provided by the authors is available with the full text of this article at Neurology.org/cp.

The Article Processing Charge was funded by the authors.

This is an open access article distributed under the terms of the Creative Commons Attribution-NonCommercial-NoDerivatives License 4.0 (CC BY-NC-ND), which permits downloading and sharing the work provided it is properly cited. The work cannot be changed in any way or used commercially without permission from the journal. 
People with epilepsy (PWE) face an increased risk of mortality compared with the general population, ${ }^{1-6}$ with a standardized mortality ratio (SMR) of 2.3 reported by population-based studies. ${ }^{2}$ Epilepsy is associated with high rates of psychiatric comorbidities and suicide, ${ }^{7-11}$ traditionally attributed to the psychosocial impact, stigmatization, and mental anguish relating to experiencing seizures. ${ }^{12,13}$ However, it is increasingly being recognized that psychiatric comorbidities have a neurobiological connection with the epileptic condition, with growing evidence suggesting a bidirectional relationship. ${ }^{14-20}$

The detrimental impact of psychopathology in PWE extends beyond the subjective experience of poorer quality of life. Patients with psychiatric disorders before epilepsy diagnosis are more likely to develop drug-resistant epilepsy. ${ }^{21}$ Similarly, higher scores of neuropsychiatric symptoms predict poorer response to antiepileptic medication in adherent patients independent of other clinical predictors, including seizure frequency before commencing treatment, epilepsy syndrome, and epileptiform abnormalities on EEG. ${ }^{22}$

PWE with psychiatric comorbidities represent a potentially vulnerable subpopulation with greater risk of mortality; however, this has been little explored, with existing research focusing on premature causes of death. ${ }^{10}$ This study uses a large cohort of adult inpatients admitted at 3 video-EEG monitoring (VEM) units over 20 years to (1) investigate all-cause mortality in PWE with psychiatric comorbidities and (2) identify psychiatric diagnoses that may benefit from more careful management because of an increased risk of mortality.

\section{Methods}

\section{Study Population and Design}

We performed a retrospective analysis from a cohort of 5,508 patients consecutively admitted for VEM to 1 of 3 comprehensive epilepsy programs in Melbourne, VIC, Australia; The Royal Melbourne Hospital $(n=2,306)$, St. Vincent's Hospital $(\mathrm{n}=1,244)$, and Austin Hospital $(\mathrm{n}=1,958)$ between January 1, 1995, and December 31, 2015.

Patients were admitted either for definitive diagnosis of an undiagnosed uncontrolled seizure disorder or for further characterization of difficult to control epilepsy to guide further management, including potential surgery. Data collection was performed by review of the medical records of each patient's admission.

\section{Epilepsy Diagnosis}

All patients were routinely evaluated with thorough examinations of their clinical history, 1-3 weeks of continuous VEM, and neuroimaging using a 1.5/3.0 T MRI with an epilepsy sequence protocol. Single photon emission tomography and fluorodeoxyglucose PET studies were also performed when clinically indicated to aid localization of epileptic focus. Epilepsy diagnoses were made at weekly multidisciplinary meetings by consensus opinion of experienced epileptologists in accordance with the International League Against Epilepsy (ILAE) guidelines ${ }^{23,24}$ on the basis of this evaluation. Captured seizures during VEM with ictal EEG recording were not required for the diagnosis of epilepsy to be made, although ictal and or interictal epileptiform EEG discharges were recorded in the majority of patients in whom epilepsy diagnosis was made. Epilepsies were classified in accordance with the 2017 ILAE classification system $^{25}$ into epilepsy types defined as (1) focal, (2) multifocal, (3) generalized, and (4) combined focal and generalized epilepsy, as well as into epilepsy syndromes of temporal lobe epilepsy (TLE), extra-TLE, genetic generalized epilepsy (GGE), and epileptic encephalopathy where enough diagnostic information was available. Epilepsies were further classified according to lesionality. Lesional epilepsy was defined as the presence of a potentially epileptogenic structural lesion on MRI. Mesial temporal sclerosis was used to describe lesional epilepsy in patients with TLE who had compatible MRI findings. Nonlesional epilepsy was defined by the absence of imaging evidence of pathology but clear epilepsy syndrome localization on VEM.

\section{Psychiatric Diagnosis}

All patients were routinely referred for neuropsychiatric assessment with the aim of identifying psychiatric comorbidities that would affect management or confound an epilepsy diagnosis. Patients were formally assessed by a neuropsychiatrist before the weekly multidisciplinary VEM meeting. Psychiatric diagnoses were informed by the Diagnostic and Statistical Manual of Mental Disorders (DSM)-IV and DSM-V. Psychiatric diagnoses were categorized into a lifetime history of depressive, anxiety, psychotic, substance misuse, and personality disorders with supervision by a neuropsychiatrist (D.V.). Psychotic disorders included postictal and interictal psychoses and excluded ictal psychoses.

\section{Exclusion Criteria}

Patients were excluded from analyses if they did not have a formal epilepsy diagnosis after comprehensive evaluation ( $\mathrm{n}$ $=2,116)$, were younger than 18 years at the time of admission $(\mathrm{n}=683)$, died of a high-grade brain tumor known at admission $(n=27)$, or if they had incomplete neuropsychiatric assessment data $(n=877)$. Reasons for incomplete neuropsychiatric data included declined assessments, unsuitability for assessment due to intellectual disability or mutism, discharge before assessment, time constraints leading to incomplete assessment, and lost reports. Patients younger than 18 years at admission were excluded to maintain consistency within the cohort as 2 of the 3 centers are exclusively adult hospitals that do not routinely admit children for VEM, and these patients are likely to represent a more severe group with refractory epilepsy in childhood. After exclusion criteria were applied, 1,805 patients were included for analysis. This cohort overlapped with that included in a recent report from our group focusing on mortality in patients with psychogenic nonepileptic seizures. ${ }^{6}$ 
Table 1 Patient Demographics by Presence of a Psychiatric Comorbidity $(n=1,805)$

\begin{tabular}{|c|c|c|c|c|c|c|c|}
\hline \multirow[b]{2}{*}{$\begin{array}{l}\text { Psychiatric } \\
\text { comorbidity status }\end{array}$} & \multicolumn{7}{|c|}{ Patients who had a complete neuropsychiatric evaluation $(n=1,805)$} \\
\hline & $\begin{array}{l}\text { No psychiatric } \\
\text { disorder }\end{array}$ & $\begin{array}{l}\text { Any psychiatric } \\
\text { disorder }\end{array}$ & $\begin{array}{l}\text { Depressive } \\
\text { disorder }\end{array}$ & $\begin{array}{l}\text { Anxiety } \\
\text { disorder }\end{array}$ & $\begin{array}{l}\text { Psychotic } \\
\text { disorder }\end{array}$ & $\begin{array}{l}\text { Substance misuse } \\
\text { disorder }\end{array}$ & $\begin{array}{l}\text { Personality } \\
\text { disorder }\end{array}$ \\
\hline $\mathbf{N}(\%)$ & $868(48)$ & $937(52)$ & $670(37)$ & $231(13)$ & $135(7)$ & $214(12)$ & $121(7)$ \\
\hline $\begin{array}{l}\text { Age at VEM, y, } \\
\text { median (IQR) }\end{array}$ & $35(26-46)$ & $37(29-47)$ & $38(30-48)$ & $36(29-47)$ & $37(30-47)$ & $35(27-43)$ & $35(26-45)$ \\
\hline Sex, female, n (\%) & $465(54)$ & $534(57)$ & $392(59)$ & $165(71)$ & $65(48)$ & $88(41)$ & $67(55)$ \\
\hline $\begin{array}{l}\text { Follow-up duration, y, } \\
\text { median (IQR) }\end{array}$ & $9(4-14)$ & $9(5-13)$ & $9(5-13)$ & $8(5-12)$ & $10(4-15)$ & $8(5-12)$ & $11(7-16)$ \\
\hline Number deceased & 60 & 87 & 63 & 16 & 15 & 19 & 14 \\
\hline
\end{tabular}

Abbreviations: IQR = interquartile range; VEM = video-EEG monitoring.

\section{Ascertainment of Mortality}

Patients were followed up from their VEM admission until June 2018. Mortality and cause of death were ascertained by linkage at this date to the Australian National Death Index (NDI), a database listing all deaths in Australia since 1980. Underlying causes of death extracted from the NDI were reported as International Classification of Diseases 10th edition codes derived from the primary cause of death listed on Australian death certificates. The cohort was also linked to the Australian National Coronial Information System (NCIS), a database of complete coronial, autopsy, and toxicology reports for all patients with reportable deaths since July 1, 2000, under The Coronial Act. Where patients received a postmortem examination, cause of death was refined based on data from the NCIS. Cases of sudden unexpected death in epilepsy (SUDEP) were reviewed independently by 2 epileptologists (T.O.B. and P.P.) and classified according to Nashef ${ }^{26}$ criteria.

\section{Statistical Analyses}

For calculation of SMRs, expected number of deaths was estimated from applying published age-, sex-, and yearspecific mortality rates in 1995-2015 from the Australian Bureau of Statistics. ${ }^{27}$ For patients who died after 2015, the 2015 general population mortality rates were applied.

Multivariable Cox proportional hazards regression was performed to assess the hazard ratio (HR) of mortality between PWE with psychiatric comorbidities and PWE without, adjusting for age at VEM and sex. This was also used to compare mortality between PWE with specific categories of psychiatric comorbidities and PWE with no history of a psychiatric disorder.

Statistical significance level was set at $p<0.05$. All statistical tests were performed by using Stata version 15 (StataCorp., College Station, TX).

\section{Standard Protocol Approvals, Registrations, and Patient Consents}

The study was approved by the Human Research Ethics Committees of St. Vincent's Hospital, Melbourne Health and
Austin Health (HREC/15/SVHM/110). For data linkage to the NDI, approval was granted by the Australian Institute of Health and Welfare Ethics Committee (EO2016/1/226). Access to the NCIS was granted by the Justice Human Research Ethics Committee (CF/16/8896).

\section{Data Availability}

Data used in analysis are available from the corresponding author on request from any qualified researcher for a period of 12 months following publication.

\section{Results}

\section{Demographics}

Demographics of the study population $(n=1,805)$ and categorization of patients with a lifetime history of a psychiatric disorder are summarized in Table 1. Fifty-two percent of patients had a history of a psychiatric disorder. Demographics of patients included for analyses compared with patients who were excluded due to lack of complete neuropsychiatric data are presented in the supplementary material (eTable 1, links. lww.com/CPJ/A300).

\section{Mortality of PWE With Psychiatric Comorbidities}

Mortality of PWE with (SMR 3.6, 95\% confidence interval [CI] 2.9-4.4; Table 2) and without a lifetime history of a comorbid psychiatric disorder (SMR 2.5, 95\% CI 1.9-3.2; Table 2) were both greater than that of the general population. On direct comparison using Cox regression analysis adjusting for the effects of age and sex, mortality remained elevated in PWE with comorbid psychiatric disorders compared with PWE without (HR 1.41, 95\% CI 1.02-1.97; Table 3; Figure 1A). In patients where the epilepsy type $(n=1,624)$ and syndrome $(n=1,537)$ were known, mortality remained elevated in PWE with comorbid psychiatric disorders compared with PWE without after additional adjustment for epilepsy type and lesionality (HR 1.54, 95\% CI 1.05-2.24; eTable 2, links.lww.com/CPJ/ A300), and epilepsy syndrome and lesionality (HR 1.51, 95\% 
Table 2 Age-Sex-Year-Specific Standardized Mortality Ratios

\begin{tabular}{|c|c|c|c|c|}
\hline Psychiatric diagnosis & Sex & Observed death & Expected death & Standardized mortality ratio $(95 \% \mathrm{Cl})$ \\
\hline \multirow[t]{3}{*}{ No psychiatric disorder } & $\mathrm{F}$ & 26 & 9.6 & $2.7(1.9-4.0)$ \\
\hline & M & 34 & 15 & $2.3(1.6-3.2)$ \\
\hline & Total & 60 & 24 & $2.5(1.9-3.2)$ \\
\hline \multirow[t]{3}{*}{ Any psychiatric disorder } & $\mathrm{F}$ & 41 & 12 & $3.3(2.4-4.5)$ \\
\hline & M & 46 & 12 & $3.8(2.9-5.1)$ \\
\hline & Total & 87 & 24 & $3.6(2.9-4.4)$ \\
\hline
\end{tabular}

Abbreviation: $\mathrm{Cl}=$ confidence interval.

CI 1.03-2.20; eTable 3). A subgroup Cox regression analysis ( $\mathrm{n}=417$ ) adjusting for the lifetime presence of tonic-clonic seizures (TCSs), which encompassed generalized TCS in patients with GGE and bilateral TCS in patients with forms of epilepsy other than GGE, demonstrated no elevated mortality in PWE with comorbid psychiatric disorders (eTable 4).

On examination of relative risk (RR) of mortality stratified by age groups, there was evidence of increased mortality in PWE with a lifetime history of a psychiatric comorbidity compared with PWE without in the under 30 age group (eFigure 1, links.lww.com/CPJ/A300); however, this did not reach the predefined statistical threshold. Within PWE with a lifetime history of psychiatric comorbidity, the RR of mortality in the under 30 age group was significantly greater than the RR of mortality in the 40-49, 50-59, and over 60 age groups (eFigure 1). Within PWE with no lifetime history of psychiatric comorbidity, the RR of mortality in the under 30 age group was significantly greater than the RR of mortality in the 50-59 and over 60 age groups (eFigure 1).

\section{Mortality of PWE With Specific Psychiatric Comorbidities}

On Cox regression and survival analyses of the effect on mortality of specific psychiatric comorbidities in epilepsy, PWE with a single comorbid depressive, anxiety, psychotic, substance misuse or personality disorder had no increased risk of mortality compared with PWE with no psychiatric comorbidity (Table 3; Figure 1, B-F). In patients where the epilepsy type and syndrome were known, no difference was observed between PWE with a single psychiatric comorbidity compared with PWE with no psychiatric comorbidity, after adjusting for the effects of epilepsy type, syndrome and lesionality (eTables 2 and 3, links.lww.com/CPJ/ A300). When the effect of specific psychiatric comorbidities on mortality regardless of the presence of other psychiatric comorbidities was examined, no significant difference was observed in mortality between PWE with a specific comorbid psychiatric disorder and PWE without (eTable 5, A-E).

\section{Cause of Death}

Of 147 deceased PWE over the study period, 87 had a lifetime history of a psychiatric disorder. Diseases of the nervous system were the most common cause of death, followed by neoplasms and external causes of mortality for both PWE with a psychiatric comorbidity and PWE without (Table 4). Thirty-six patients met the criteria for either definite $(n=29)$ or probable SUDEP $(n=7)$, with the majority of these deaths $(89 \%)$ occurring in patients younger than 50 years. The rates of definite or probable SUDEP were 1.62 and 2.49 cases per 1,000 person-years in PWE with no lifetime psychiatric comorbidity and in PWE with psychiatric comorbidity, respectively; however, the difference did not reach statistical significance.

\section{Discussion}

This study demonstrates that a lifetime history of any comorbid psychiatric disorder confers a significantly greater risk of mortality in PWE on top of the risk due to epilepsy alone. The subgroup analyses suggest that this is irrespective of epilepsy type, syndrome, or lesionality.

Of interest, there was no diagnostic category of psychiatric disorders (depressive, anxiety, psychotic, substance misuse or personality disorders), which specifically conferred an increased risk of mortality in PWE with a single comorbid psychiatric diagnosis (Table 3). This discrepancy may be due to smaller sample sizes and the heterogeneity of presentations within these categories. In addition, there may be factors other than psychiatric diagnosis that may increase mortality in PWE, such as severity of psychiatric illness or having multiple comorbid psychiatric disorders, which should be explored in future studies.

Consistent with previous studies, ${ }^{28,29}$ neoplasms and diseases of the circulatory system were among the 4 most common causes of death in both PWE with and without psychiatric comorbidities. We report a higher prevalence of deaths from diseases of the nervous system than previous studies. This likely reflects our hospital-based cohort, which selects for more 
Table 3 Cox Proportional Hazards Model of Time to Death by Psychiatric Disorders

\begin{tabular}{|c|c|c|c|c|c|c|}
\hline & \multicolumn{6}{|l|}{ Hazard ratio $(95 \% \mathrm{CI})$} \\
\hline & $\begin{array}{l}\text { Any psychiatric } \\
\text { disorder }(n=1,805)\end{array}$ & $\begin{array}{l}\text { Depressive } \\
\text { disorder }(n=1,235)\end{array}$ & $\begin{array}{l}\text { Anxiety } \\
\text { disorder }(n=933)\end{array}$ & $\begin{array}{l}\text { Psychotic } \\
\text { disorder }(n=923)\end{array}$ & $\begin{array}{l}\text { Substance } \\
\text { misuse }(n=928)\end{array}$ & $\begin{array}{l}\text { Personality } \\
\text { disorder }(n=912)\end{array}$ \\
\hline $\begin{array}{l}\text { Psychiatric comorbidity } \\
\text { status vs no psychiatric } \\
\text { disorder }\end{array}$ & $1.41(1.02-1.97)$ & $1.45(0.96-2.21)$ & $0.77(0.24-2.47)$ & $1.66(0.72-3.86)$ & $1.26(0.50-3.14)$ & $1.35(0.58-3.16)$ \\
\hline Age at VEM & $1.04(1.02-1.05)$ & $1.04(1.02-1.05)$ & $1.03(1.01-1.05)$ & $1.03(1.02-1.05)$ & $1.04(1.02-1.05)$ & $1.04(1.02-1.06)$ \\
\hline Male sex & $1.54(1.11-2.13)$ & $1.58(1.06-2.36)$ & $1.45(0.88-2.39)$ & $1.60(0.98-2.61)$ & $1.38(0.84-2.26)$ & $1.49(0.91-2.43)$ \\
\hline
\end{tabular}

Abbreviations: $\mathrm{Cl}=$ confidence interval; $\mathrm{VEM}=$ video-EEG monitoring.

severe, drug-resistant epilepsy compared with communitybased cohorts of most previous studies. We also found several cases of deaths that were reported as diseases of the nervous system only after coronial examination. It is possible that previous studies that did not have access to coronial or autopsy data may have underestimated the true prevalence of diseases of the nervous system in PWE.

The prevalence of external causes of death (i.e., accidental deaths or suicides) in both PWE with and without psychiatric comorbidities was considerably greater than previous mortality studies in PWE, which have largely been community-based. Although both groups had comparable rates of death from external causes (Table 4), PWE with psychiatric comorbidities had 5 cases of confirmed suicide and 1 case of potential suicide compared with only 2 cases of confirmed suicide in PWE without psychiatric comorbidities. This is consistent with a recent study ${ }^{10}$ demonstrating an increased risk of death due to suicide in PWE with psychiatric disorders compared with PWE without. Our findings show that accidents remain an important and major cause of death in patients with treatment refractory epilepsy and confirm that PWE with psychiatric comorbidities remain at especially high risk of death from suicides. Moreover, suicides were still more common in PWE with comorbid psychiatric illness despite extensive psychiatric evaluation, highlighting the importance of timely psychiatric management and follow-up.

Overall, 24\% of deaths in our cohort were due to definite or probable SUDEP, accounting for the majority of deaths from diseases of the nervous system. The rate of SUDEP in our cohort is consistent with the range of $1.2-6.3$ cases per 1,000 person-years reported in previous studies. ${ }^{2} \mathrm{We}$ found a trend for the rate of definite or probable SUDEP per 1,000 personyears in PWE to be higher in those with a lifetime history of psychiatric comorbidity (2.49) compared with those without (1.62). No previous SUDEP studies have examined the effects of psychiatric comorbidities. Only 1 previous study investigating the prevalence of SUDEP in PWE has been based mainly on autopsy findings, which reported the highest incidence of SUDEP (6.3 per 1,000 person-years). ${ }^{30}$ However, this study only examined patients referred for epilepsy surgery, potentially reflecting a population with more severe epilepsy, whereas our cohort included both patients referred for surgery and patients referred for further medical management. Our cohort is more than 8 times larger with over double the length of follow up time. Consistent with previous literature, the prevalence of SUDEP was greatest in ages $20-40$ years. $^{31,32}$ Our results confirm the danger of SUDEP in drug-resistant epilepsy, in particular those with a history of psychiatric comorbidities, and the importance of addressing this risk in this vulnerable group of patients.

Otherwise, we found that both PWE with psychiatric comorbidities and PWE without had a similar distribution of causes of death. This finding raises the question of whether the presence of a psychiatric comorbidity may augment epilepsy via shared underlying pathologic mechanisms such as common changes in neuroanatomy or neurotransmitter disturbance, genetic susceptibility, or environmental factors. Several previous studies have established a complex bidirectional relationship between epilepsy and psychiatric disorders, whereby psychiatric illness may represent a marker of decreased seizure threshold and/or the presence of seizures may increase one's susceptibility to develop psychiatric illness. ${ }^{16,17,30,33-38}$ We did not explore this relationship as data relating to the age at onset of epilepsy and psychiatric disorders were not systematically available.

The key strengths of our study include its large sample size, utilization of VEM, and specialist evaluation, which is considered to be gold standard for epilepsy diagnosis. Mortality data were accurate and complete through linkage to the NDI and NCIS. Psychiatric diagnoses were determined by full neuropsychiatric assessment. Although previous studies have found some psychiatric diagnoses, such as anxiety, to be underdetected without the use of structured diagnostic instruments, ${ }^{39}$ clinical neuropsychiatric assessment may be more sensitive in detecting atypical symptoms in other psychiatric diagnoses that are not uncommon in PWE. 
Figure 1 Kaplan-Meier Plots of Survival Comparing PWE With and PWE Without Psychiatric Comorbidities

A

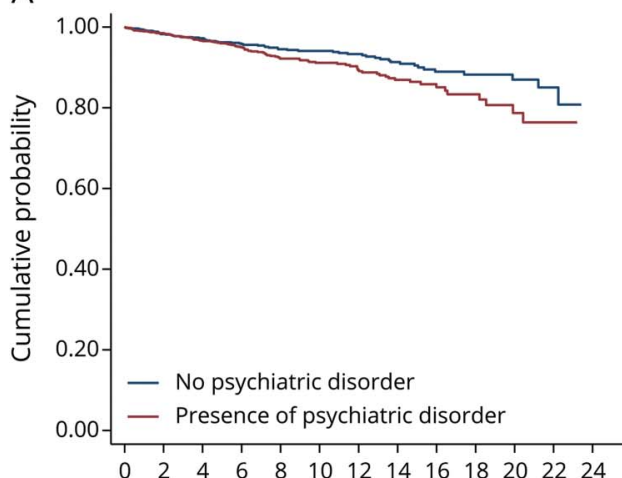
Number at risk:

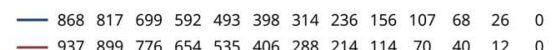

C

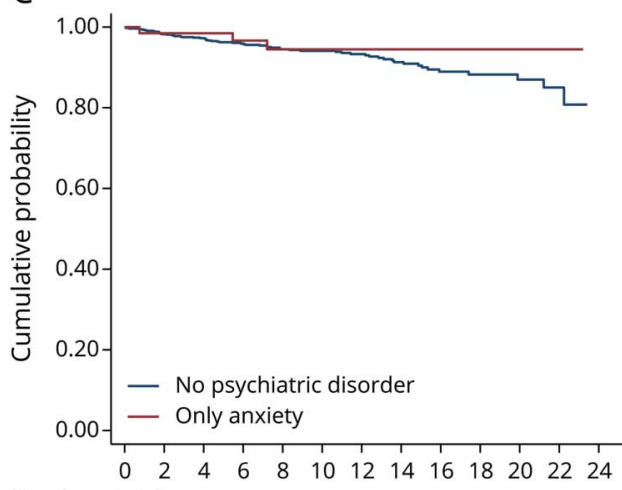
Number at risk:

— $868817699592493398314 \quad 236156 \quad 107 \quad 68 \quad 26 \quad 0$

$\begin{array}{llllllllllllll}-65 & 62 & 56 & 51 & 39 & 29 & 22 & 19 & 6 & 4 & 2 & 1 & 0\end{array}$

$\mathrm{E}$

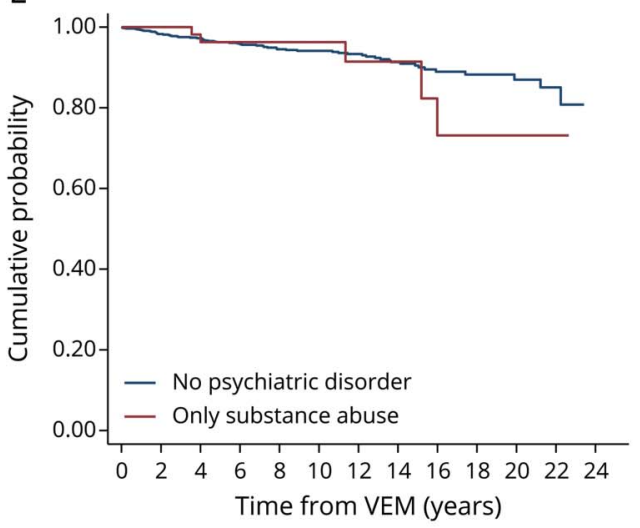

Number at risk:

— $868 \begin{array}{llllllllllll}817 & 699 & 592 & 493 & 398 & 314 & 236 & 156 & 107 & 68 & 26 & 0\end{array}$
B

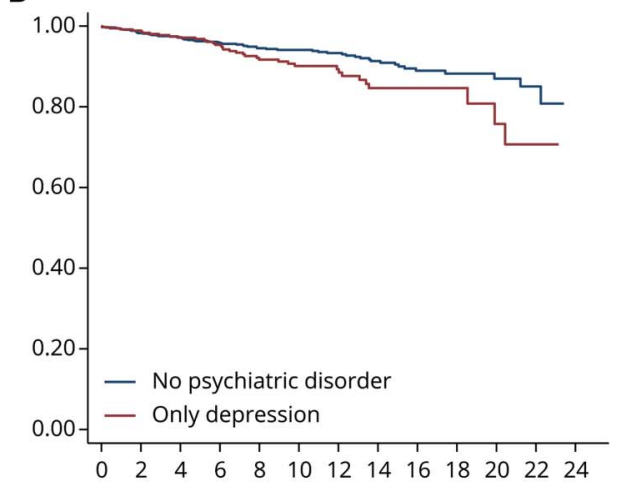

Number at risk:

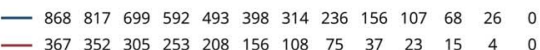

D

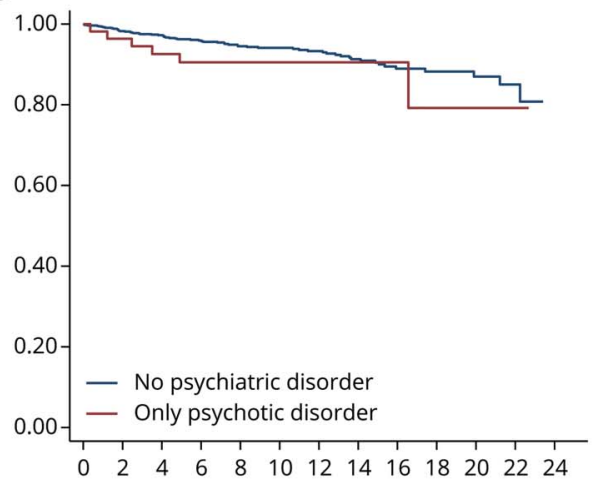

Number at risk:

— $868 \begin{array}{llllllllllll}817 & 699 & 592 & 493 & 398 & 314 & 236 & 156 & 107 & 68 & 26 & 0\end{array}$

$\begin{array}{llllllllllllll}55 & 53 & 48 & 44 & 38 & 31 & 21 & 14 & 10 & 6 & 4 & 1 & 0\end{array}$

$\mathrm{F}$

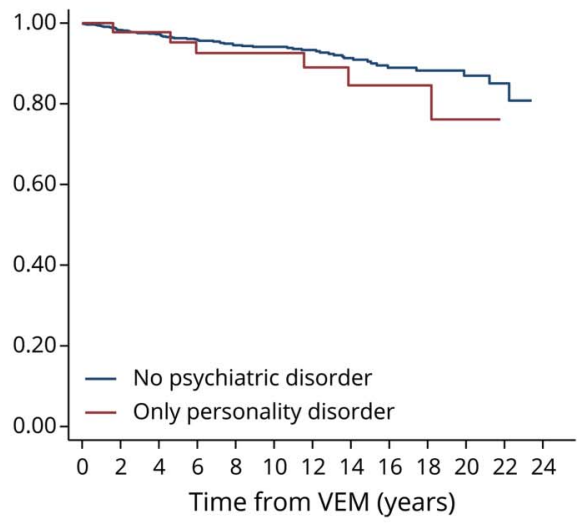

Number at risk:

— $868817699592493398 \quad 314236156107 \quad 68 \quad 26 \quad 0$

$\begin{array}{lllllllllllll}4 & 42 & 39 & 35 & 34 & 28 & 24 & 19 & 16 & 11 & 5 & 0 & 0\end{array}$

(A-F) The navy line represents the cumulative probability of death for people with epilepsy (PWE) with no psychiatric comorbidities admitted for video-EEG monitoring (VEM) over a period of 20 years. The maroon lines represent the cumulative probability of death in the groups of PWE with any psychiatric comorbidity, PWE with only depressive disorders, PWE with only anxiety disorders, PWE with only psychotic disorders, PWE with only substance misuse disorders, and PWE with only personality disorders admitted for VEM over a period of 20 years in parts A-F, respectively. Univariable Cox proportional hazards regression was used to compare the mortality between PWE with no psychiatric comorbidities and the respective group in each part. (A) In comparison to PWE with no psychiatric comorbidities, a significantly increased hazard ratio of mortality was observed in PWE with any psychiatric comorbidity (hazard ratio [HR] 1.41, 95\% confidence interval [CI] 1.02-1.97). (B) In comparison to PWE with no psychiatric comorbidities, no significant difference was observed in the hazard ratio of mortality in PWE with comorbid depressive disorders only (HR 1.45, 95\% Cl 0.96-2.21). (C) In comparison to PWE with no psychiatric comorbidities, no significant difference was observed in the hazard ratio of mortality in PWE with comorbid anxiety disorders only (HR 0.77,95\% Cl 0.24-2 47). (D) In comparison to PWE with no psychiatric comorbidities, no significant difference was observed in the hazard ratio of mortality in PWE with comorbid psychotic disorders only (HR 1.66, 95\% CI 0.72-3.86). (E) In comparison with PWE with no psychiatric comorbidities, no significant difference was observed in the hazard ratio of mortality in PWE with comorbid substance misuse disorders only (HR 1.26,95\% Cl 0.50-3.14). (F) In comparison with PWE with no psychiatric comorbidities, no significant difference was observed in the hazard ratio of mortality in PWE with comorbid personality disorders only (HR 1.35, 95\% CI 0.58-3.16). 
Table 4 Distribution of Cause of Death by Psychiatric Comorbidity

\begin{tabular}{|c|c|c|c|}
\hline \multirow{2}{*}{$\begin{array}{l}\text { Cause of death according to ICD-10-CM } \\
\text { chapter codes }\end{array}$} & \multicolumn{3}{|c|}{ No. of deceased (\% of deceased of each subpopulation) } \\
\hline & No psychiatric disorder & Any psychiatric disorder & Total \\
\hline I. Certain infectious and parasitic diseases & $0(0)$ & $1(1)$ & $1(1)$ \\
\hline II. Neoplasms & $11(18)$ & $13(15)$ & $24(16)$ \\
\hline $\begin{array}{l}\text { IV. Endocrine, nutritional, and metabolic } \\
\text { diseases }\end{array}$ & $0(0)$ & $5(6)$ & $5(3)$ \\
\hline V. Mental and behavioral disorders & $2(3)$ & $1(1)$ & $3(2)$ \\
\hline VI. Diseases of the nervous system & $20(33)$ & $28(32)$ & $48(33)$ \\
\hline SUDEP (definite or probable) & $14(23)$ & $22(25)$ & $36(24)$ \\
\hline IX. Diseases of the circulatory system & $7(12)$ & $12(14)$ & $19(13)$ \\
\hline X. Diseases of the respiratory system & $3(5)$ & $3(3)$ & $6(4)$ \\
\hline XI. Diseases of the digestive system & $2(3)$ & $0(0)$ & $2(1)$ \\
\hline XIV. Diseases of the genitourinary system & $3(5)$ & $0(0)$ & $3(2)$ \\
\hline $\begin{array}{l}\text { XVIII. Symptoms, signs, and abnormal } \\
\text { clinical and laboratory findings, not } \\
\text { elsewhere classified }\end{array}$ & $2(3)$ & $7(8)$ & $9(6)$ \\
\hline $\begin{array}{l}\text { XIX. Injury, poisoning, and certain other } \\
\text { consequences of external causes }\end{array}$ & $0(0)$ & $1(1)$ & $1(1)$ \\
\hline $\begin{array}{l}\text { XX. External causes of morbidity and } \\
\text { mortality }\end{array}$ & $10(17)$ & $16(18)$ & $26(18)$ \\
\hline Unintentional causes of death & $8(13)$ & $10(11)$ & $18(12)$ \\
\hline Confirmed suicide & $2(3)$ & $5(6)$ & $7(5)$ \\
\hline $\begin{array}{l}\text { External cause of death of } \\
\text { undetermined intent }\end{array}$ & $0(0)$ & $1(1)$ & $1(1)$ \\
\hline Total no. of deceased patients & 60 & 87 & 147 \\
\hline
\end{tabular}

Abbreviations: ICD-10-CM = International Classification of Diseases, 10th edition, Clinical Modification; SUDEP = sudden unexpected death in epilepsy.

Limitations of our study include its retrospective nature, number of deceased patients despite our sizeable cohort, an average follow up time of 10 years, and that patients admitted for VEM evaluation often have drug-resistant epilepsy, so results may not be generalizable to a community-based population. A significant proportion of patients were excluded from analyses due to lack of neuropsychiatric data. Of note, there was a greater representation of focal epilepsies in those who had neuropsychiatric data available compared with those who did not. There is thus a potential selection bias for patients who were referred for epilepsy surgery. Excluded patients may represent a more unwell population due to the higher proportion of generalized epilepsy who are nonsurgical candidates, which may also explain the substantially larger proportion of deaths in this group. In addition, although our exclusion of individuals younger than 18 years at the time of admission does not exclude childhood-onset epilepsy patients presenting in adulthood, extrapolation of results to patients with refractory epilepsy in childhood is limited.

We used the lifetime presence of TCS as a surrogate marker for epilepsy severity; however, as this variable was only available for a quarter of the total cohort, it was only adjusted for in a subgroup analysis (Table 4). Although the findings of this analysis suggest that the effect of epilepsies that manifest as TCS may be a potential confounder, the lifetime presence of TCS is a relatively poor surrogate for epilepsy severity, especially at the time of death. A number of other potential confounding variables were not adjusted for in our analysis, such as whether remission had been achieved, number of previously failed antiepileptic medications (which may be more robust markers of epilepsy severity), and medical comorbidities including those associated with psychiatric conditions. The potential confounding effect of polypharmacy, i.e., whether particular combinations of antiepileptic drugs and psychotropic agents may increase or decrease seizure threshold, is poorly understood and is worth exploring in future studies.

In conclusion, this study found that the presence of comorbid psychiatric disorders in adult PWE is associated with increased all-cause mortality, with a quarter of patients dying of SUDEP. These findings highlight the importance 


\section{TAKE-HOME POINTS}

$\rightarrow$ Adults with epilepsy with comorbid psychiatric illness have an elevated risk of mortality on top of that conferred by having epilepsy alone, in the drugresistant epilepsy population.

$\rightarrow$ Adults with epilepsy with and without comorbid psychiatric illness have a similar distribution of cause of death.

$\rightarrow$ Sudden unexplained death in epilepsy remains a major cause of death in the drug-resistant epilepsy population.

of identifying and treating psychiatric comorbidities in PWE.

\section{Study Funding}

The National Health and Medical Research Council (APP1091593), the RMH Neuroscience Foundation, and Monash University.

\section{Disclosure}

G. Tao, C. Auvrez, R. Nightscales, S. Barnard, L. McCartney, and C.B. Malpas report no disclosures relevant to the manuscript. P. Perucca is supported by the National Health and Medical Research Council (APP1163708), the Epilepsy Foundation, the Royal Australasian College of Physicians, and Melbourne Health, and his institution has received speaker honoraria or consultancy fees from Eisai, UCB Pharma, Sun Pharma, Novartis, and Supernus. Z. Chen, S. Adams, A. McIntosh, S. Ignatiadis, P. O’Brien, and M.J. Cook report no disclosures relevant to the manuscript. P. Kwan is supported by a Medical Research Future Fund Practitioner Fellowship (MRF1136427), and he reports research grants from UCB Pharma and Eisai, personal fees from UCB Pharma and Eisai, and nonfinancial support from Novartis; this support is unrelated to this study. S.F. Berkovic is supported by the National Health and Medical Research Council (APP1091593) and has received speaker honoraria or consultancy fees from Eisai, UCB Pharma, and Praxis. W. D'Souza and D. Velakoulis report no disclosures relevant to the manuscript. T.J. O'Brien reports grants and personal fees from Eisai, UCB Pharma, and Zynerba and is supported by grants from the NHMRC, National Institute of Neurological Disorders and Stroke, Monash University, and the RMH Neuroscience Foundation. Full disclosure form information provided by the authors is available with the full text of this article at Neurology.org/cp.

\section{Publication History}

Received by Neurology: Clinical Practice February 4, 2021. Accepted in final form May 7, 2021.

\begin{tabular}{|c|c|c|}
\hline Name & Location & Contribution \\
\hline Gerard Tao, MD & $\begin{array}{l}\text { The University of } \\
\text { Melbourne, Victoria, } \\
\text { Australia }\end{array}$ & $\begin{array}{l}\text { Acquisition of data, } \\
\text { interpretation of data, } \\
\text { and drafting of the } \\
\text { manuscript for } \\
\text { intellectual content }\end{array}$ \\
\hline $\begin{array}{l}\text { Clarissa Auvrez, } \\
\text { MD }\end{array}$ & $\begin{array}{l}\text { The University of } \\
\text { Melbourne, Victoria, } \\
\text { Australia }\end{array}$ & $\begin{array}{l}\text { Acquisition of data, } \\
\text { interpretation of data, } \\
\text { and drafting of the } \\
\text { manuscript for } \\
\text { intellectual content }\end{array}$ \\
\hline $\begin{array}{l}\text { Russell } \\
\text { Nightscales, } \\
\text { BSc(Hons) }\end{array}$ & $\begin{array}{l}\text { Monash University, } \\
\text { Melbourne, Victoria, } \\
\text { Australia }\end{array}$ & $\begin{array}{l}\text { Major role in acquisition } \\
\text { of data and interpretation } \\
\text { of data }\end{array}$ \\
\hline $\begin{array}{l}\text { Sarah Barnard, } \\
\text { MIPH }\end{array}$ & $\begin{array}{l}\text { Monash University, } \\
\text { Melbourne, Victoria, } \\
\text { Australia }\end{array}$ & $\begin{array}{l}\text { Major role in acquisition } \\
\text { of data and interpretation } \\
\text { of data }\end{array}$ \\
\hline $\begin{array}{l}\text { Lara McCartney, } \\
\text { MBBS }\end{array}$ & $\begin{array}{l}\text { The University of } \\
\text { Melbourne, Victoria, } \\
\text { Australia }\end{array}$ & $\begin{array}{l}\text { Acquisition of data, } \\
\text { interpretation of data, and } \\
\text { revised the manuscript for } \\
\text { intellectual content }\end{array}$ \\
\hline $\begin{array}{l}\text { Charles B. } \\
\text { Malpas, PhD }\end{array}$ & $\begin{array}{l}\text { The University of } \\
\text { Melbourne, Victoria, } \\
\text { Australia }\end{array}$ & $\begin{array}{l}\text { Oversight of study design, } \\
\text { interpretation of data, and } \\
\text { revised the manuscript for } \\
\text { intellectual content }\end{array}$ \\
\hline $\begin{array}{l}\text { Piero Perucca, } \\
\text { MD }\end{array}$ & $\begin{array}{l}\text { Monash University, } \\
\text { Melbourne, Victoria, } \\
\text { Australia }\end{array}$ & $\begin{array}{l}\text { Role in study design, data } \\
\text { collection, and } \\
\text { interpretation, revised the } \\
\text { manuscript for intellectual } \\
\text { content, and reviewed } \\
\text { NCIS data to classify } \\
\text { categories of sudden } \\
\text { death }\end{array}$ \\
\hline $\begin{array}{l}\text { Zhibin Chen, } \\
\text { MBiostat, PhD }\end{array}$ & $\begin{array}{l}\text { Monash University, } \\
\text { Melbourne, Victoria, } \\
\text { Australia }\end{array}$ & $\begin{array}{l}\text { Statistical analysis of data } \\
\text { and production of figures }\end{array}$ \\
\hline $\begin{array}{l}\text { Sophia Adams, } \\
\text { MBBS }\end{array}$ & $\begin{array}{l}\text { The University of } \\
\text { Melbourne, Victoria, } \\
\text { Australia }\end{array}$ & $\begin{array}{l}\text { Major role in acquisition } \\
\text { of data, interpretation of } \\
\text { data, and revised the } \\
\text { manuscript for intellectual } \\
\text { content }\end{array}$ \\
\hline $\begin{array}{l}\text { Anne Mclntosh, } \\
\text { PhD }\end{array}$ & $\begin{array}{l}\text { The University of } \\
\text { Melbourne, Victoria, } \\
\text { Australia }\end{array}$ & $\begin{array}{l}\text { Oversight of study design, } \\
\text { interpretation of data, and } \\
\text { revised the manuscript for } \\
\text { intellectual content }\end{array}$ \\
\hline $\begin{array}{l}\text { Sophia Ignatiadis, } \\
\text { MSc }\end{array}$ & $\begin{array}{l}\text { The University of } \\
\text { Melbourne, Victoria, } \\
\text { Australia }\end{array}$ & $\begin{array}{l}\text { Acquisition of data and } \\
\text { interpretation of data }\end{array}$ \\
\hline $\begin{array}{l}\text { Patrick O'Brien, } \\
\text { MBBS }\end{array}$ & $\begin{array}{l}\text { The University of } \\
\text { Melbourne, Victoria, } \\
\text { Australia }\end{array}$ & $\begin{array}{l}\text { Acquisition of data and } \\
\text { interpretation of data }\end{array}$ \\
\hline Mark J. Cook, MD & $\begin{array}{l}\text { The University of } \\
\text { Melbourne, Victoria, } \\
\text { Australia }\end{array}$ & $\begin{array}{l}\text { Role in study design and } \\
\text { revised the manuscript for } \\
\text { intellectual content }\end{array}$ \\
\hline Patrick Kwan, MD & $\begin{array}{l}\text { The University of } \\
\text { Melbourne, Victoria, } \\
\text { Australia }\end{array}$ & $\begin{array}{l}\text { Role in study design and } \\
\text { revised the manuscript for } \\
\text { intellectual content }\end{array}$ \\
\hline $\begin{array}{l}\text { Samuel F. } \\
\text { Berkovic, MD }\end{array}$ & $\begin{array}{l}\text { The University of } \\
\text { Melbourne, Victoria, } \\
\text { Australia }\end{array}$ & $\begin{array}{l}\text { Principle investigator, } \\
\text { oversight of study design, } \\
\text { interpretation of data, and } \\
\text { revised the manuscript for } \\
\text { intellectual content }\end{array}$ \\
\hline
\end{tabular}




\section{Appendix (continued)}

\begin{tabular}{lll}
\hline Name & Location & Contribution \\
\hline $\begin{array}{l}\text { Wendyl D'Souza, } \\
\text { MBChB, PhD }\end{array}$ & $\begin{array}{l}\text { The University of } \\
\text { Melbourne, Victoria, } \\
\text { Australia }\end{array}$ & $\begin{array}{l}\text { Principle investigator, } \\
\text { oversight of study design, } \\
\text { interpretation of data, and } \\
\text { revised the manuscript for } \\
\text { intellectual content }\end{array}$ \\
\hline $\begin{array}{l}\text { Dennis } \\
\text { Velakoulis, MBBS }\end{array}$ & $\begin{array}{l}\text { The University of } \\
\text { Australia }\end{array}$ & $\begin{array}{l}\text { Principle investigator, } \\
\text { oversight of study design, } \\
\text { interpretation of data, and } \\
\text { revised the manuscript for } \\
\text { intellectual content }\end{array}$ \\
\hline $\begin{array}{l}\text { Terence J. } \\
\text { O'Brien, MD }\end{array}$ & $\begin{array}{l}\text { Monash University, } \\
\text { Melbourne, Victoria, }\end{array}$ & $\begin{array}{l}\text { Principle investigator, } \\
\text { oversight of study design, } \\
\text { interpretation of data, } \\
\text { drafting of the manuscript } \\
\text { for intellectual content, } \\
\text { and reviewed NCIS data to } \\
\text { classify the categories of } \\
\text { sudden death }\end{array}$ \\
& &
\end{tabular}

\section{References}

1. Hitiris N, Mohanraj R, Norrie J, et al. Mortality in epilepsy. Epilepsy Behav. 2007; 10(3):363-376.

2. Thurman DJ, Logroscino G, Beghi E, et al. The burden of premature mortality of epilepsy in high-income countries: a systematic review from the Mortality Task Force of the International League Against Epilepsy. Epilepsia. 2017;58(1):17-26.

3. Nevalainen O, Ansakorpi H, Simola M, et al. Epilepsy-related clinical characteristics and mortality: a systematic review and meta-analysis. Neurology. 2014;83(21): 1968-1977.

4. Wicks P, Fountain NB. Patient assessment of physician performance of epilepsy quality-of-care measures. Neurol Clin Pract. 2012;2(4):335-342.

5. Shankar R, Cox D, Jalihal V, et al. Sudden unexpected death in epilepsy (SUDEP) development of a safety checklist. Seizure. 2013;22(10):812-817.

6. Nightscales R, McCartney L, Auvrez C, et al. Mortality in patients with psychogenic nonepileptic seizures. Neurology. 2020;95(6):e643-e652.

7. Gaitatzis A, Trimble MR, Sander JW. The psychiatric comorbidity of epilepsy. Acta Neurol Scand. 2004;110(4):207-220.

8. Kanner AM. Depression in epilepsy: a frequently neglected multifaceted disorder. Epilepsy Behav. 2003;4(suppl 4):11-19.

9. Stefanello S, Marin-Leon L, Fernandes PT, et al. Psychiatric comorbidity and suicida behavior in epilepsy: a community-based case-control study. Epilepsia. 2010;51(7): $1120-1125$.

10. Fazel S, Wolf A, Langstrom N, et al. Premature mortality in epilepsy and the role of psychiatric comorbidity: a total population study. Lancet. 2013;382(9905): 1646-1654

11. Adams SJ, Velakoulis D, Kaye AH, et al. Psychiatric history does not predict seizure outcome following temporal lobectomy for mesial temporal sclerosis. Epilepsia. 2012, 53(10):1700-1704.

12. Hoppe C, Elger CE. Depression in epilepsy: a critical review from a clinical perspective. Nat Rev Neurol. 2011;7(8):462-472.
13. de Boer HM, Mula M, Sander JW. The global burden and stigma of epilepsy. Epilepsy Behav. 2008;12(4):540-546.

14. Hesdorffer DC, Hauser WA, Olafsson E, et al. Depression and suicide attempt as risk factors for incident unprovoked seizures. Ann Neurol. 2006;59(1):35-41.

15. Panelli RJ, Kilpatrick C, Moore SM, et al. The Liverpool Adverse Events Profile relation to AED use and mood. Epilepsia. 2007;48(3):456-463.

16. Hesdorffer DC, Ishihara L, Mynepalli L, et al. Epilepsy, suicidality, and psychiatric disorders: a bidirectional association. Ann Neurol. 2012;72(2):184-191.

17. Adelow C, Andersson T, Ahlbom A, et al. Hospitalization for psychiatric disorder before and after onset of unprovoked seizures/epilepsy. Neurology. 2012;78(6): 396-401.

18. Jones NC, Salzberg MR, Kumar G, et al. Elevated anxiety and depressive-like behavior in a rat model of genetic generalized epilepsy suggesting common causation. Exp Neurol. 2008;209(1):254-260.

19. Bouilleret V, Hogan RE, Velakoulis D, et al. Morphometric abnormalities and hyperanxiety in genetically epileptic rats: a model of psychiatric comorbidity? Neuroimage. 2009;45(2):267-274.

20. Jones NC, Kumar G, O’Brien TJ, et al. Anxiolytic effects of rapid amygdala kindling, and the influence of early life experience in rats. Behav Brain Res. 2009;203(1):81-87.

21. Hitiris N, Mohanraj R, Norrie J, et al. Predictors of pharmacoresistant epilepsy. Epilepsy Res. 2007;75(2-3):192-196.

22. Petrovski S, Szoeke CE, Jones NC, et al. Neuropsychiatric symptomatology predicts seizure recurrence in newly treated patients. Neurology. 2010;75(11):1015-1021.

23. Fisher RS, Acevedo C, Arzimanoglou A, et al. ILAE official report: a practical clinical definition of epilepsy. Epilepsia. 2014;55(4):475-482.

24. Fisher RS, van Emde Boas W, Blume W, et al. Epileptic seizures and epilepsy: definitions proposed by the International League Against Epilepsy (ILAE) and the International Bureau for Epilepsy (IBE). Epilepsia. 2005;46(4):470-472

25. Scheffer IE, Berkovic S, Capovilla G, et al. ILAE classification of the epilepsies: position paper of the ILAE Commission for Classification and Terminology. Epilepsia. 2017;58(4):512-521.

26. Nashef L, So EL, Ryvlin P, et al. Unifying the definitions of sudden unexpected death in epilepsy. Epilepsia. 2012;53(2):227-233.

27. ABS. 3302.0 ABS.Stat Datasets. Deaths, Year of Occurrence, Age at Death, Age Specific Death Rates, Sex, States, Territories and Australia. Australian Bureau of Statistics; 2015.

28. Keezer MR, Bell GS, Neligan A, et al. Cause of death and predictors of mortality in a community-based cohort of people with epilepsy. Neurology. 2016;86(8):704-712.

29. Gaitatzis A, Sander JW. The mortality of epilepsy revisited. Epileptic Disord. 2004, 6(1):3-13.

30. Nilsson L, Ahlbom A, Farahmand BY, et al. Mortality in a population-based cohort of epilepsy surgery patients. Epilepsia. 2003;44(4):575-581.

31. Devinsky O, Hesdorffer DC, Thurman DJ, et al. Sudden unexpected death in epilepsy: epidemiology, mechanisms, and prevention. Lancet Neurol. 2016;15(10):1075-1088.

32. Langan $Y$, Sudden unexpected death in epilepsy (SUDEP): risk factors and case control studies. Seizure. 2000;9(3):179-183.

33. Tellez-Zenteno JF, Patten SB, Jette N, et al. Psychiatric comorbidity in epilepsy: a population-based analysis. Epilepsia. 2007;48(12):2336-2344.

34. Kanner AM. Depression and epilepsy: a bidirectional relation? Epilepsia. 2011;52(suppl 1):21-27.

35. Kanner AM. Psychiatric issues in epilepsy: the complex relation of mood, anxiety disorders, and epilepsy. Epilepsy Behav. 2009;15(1):83-87.

36. Chang YT, Chen PC, Tsai IJ, et al. Bidirectional relation between schizophrenia and epilepsy: a population-based retrospective cohort study. Epilepsia. 2011;52(11): 2036-2042.

37. Qin $\mathrm{P}, \mathrm{Xu} \mathrm{H}$, Laursen TM, et al. Risk for schizophrenia and schizophrenia-like psychosis among patients with epilepsy: population based cohort study. BMJ. 2005; 331(7507):23.

38. Wotton CJ, Goldacre MJ. Coexistence of schizophrenia and epilepsy: record-linkage studies. Epilepsia. 2012;53(4):e71-4.

39. Scott AJ, Sharpe L, Hunt C, et al. Anxiety and depressive disorders in people with epilepsy: a meta-analysis. Epilepsia. 2017;58(6):973-982. 


\title{
Neurology ${ }^{\circ}$ Clinical Practice
}

\author{
Association Between Psychiatric Comorbidities and Mortality in Epilepsy \\ Gerard Tao, Clarissa Auvrez, Russell Nightscales, et al.
}

Neurol Clin Pract 2021;11;429-437 Published Online before print July 12, 2021

DOI 10.1212/CPJ.0000000000001114

This information is current as of July 12, 2021

\section{Updated Information \& Services}

\section{References}

Citations

Subspecialty Collections

Permissions \& Licensing

Reprints including high resolution figures, can be found at:

http://cp.neurology.org/content/11/5/429.full.html

This article cites 38 articles, 2 of which you can access for free at: http://cp.neurology.org/content/11/5/429.full.html\#\#ref-list-1

This article has been cited by 1 HighWire-hosted articles: http://cp.neurology.org/content/11/5/429.full.html\#\#otherarticles

This article, along with others on similar topics, appears in the following collection(s): All Epilepsy/Seizures

http://cp.neurology.org//cgi/collection/all_epilepsy_seizures

All Psychiatric disorders

http://cp.neurology.org//cgi/collection/all_psychiatric_disorders

Video/ EEG use in epilepsy

http://cp.neurology.org//cgi/collection/video__eeg_use_in_epilepsy

Information about reproducing this article in parts (figures,tables) or in its entirety can be found online at:

http://cp.neurology.org/misc/about.xhtml\#permissions

Information about ordering reprints can be found online:

http://cp.neurology.org/misc/addir.xhtml\#reprintsus

Neurol Clin Pract is an official journal of the American Academy of Neurology. Published continuously since 2011, it is now a bimonthly with 6 issues per year. Copyright Copyright @ 2021 The Author(s). Published by Wolters Kluwer Health, Inc. on behalf of the American Academy of Neurology.. All rights reserved. Print ISSN: 2163-0402. Online ISSN: $2163-0933$.

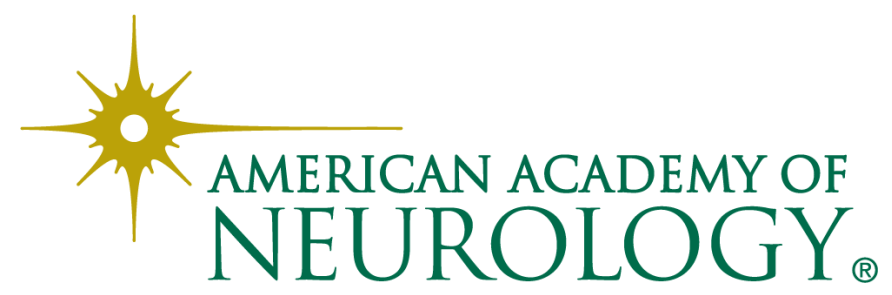

